\title{
Qualitative SEM/EDS analysis of microleakage and apical gap formation of adhesive root-filling materials
}

Soraia de Fátima Carvalho SOUZA¹, Carlos FRANCCI ${ }^{2}$, Antonio C. BOMBANA ${ }^{3}$, Silvia KENSHIMA ${ }^{4}$, Lúcia P. BARROSO5, Liz Z. D’AGOSTINO ${ }^{6}$, Alessandro D. LOGUERCIO'

\footnotetext{
1- DDS, MSc, PhD, Adjunct Professor, School of Dentistry, Federal University of Maranhão, São Luiz, MA, Brazil.

2- DDS, MSc, PhD, Associate Professor, Department of Dental Materials, University of São Paulo, São Paulo, SP, Brazil.

3- DDS, MSc, PhD, Honorary Professor, Department of Restorative Dentistry, University of São Paulo, São Paulo, SP, Brazil.

4- DDS, MSc, PhD, Department of Dental Materials, University of São Paulo, São Paulo, SP, Brazil.

5- DDS, MSc, PhD, Associate Professor, Department of Mathematics and Statistics, University of São Paulo, São Paulo, SP, Brazil.

6- MSc, Department of Mining and Petroleum Engineering, University of São Paulo, São Paulo, SP, Brazil.

7- DDS, MSc, PhD, Adjunct Professor, State University of Ponta Grossa, Ponta Grossa, PR, Brazil.
}

Corresponding address: Soraia de Fatima Carvalho Souza - Faculdade de Odontologia - Universidade Federal do Maranhão (UFMA) - Av. dos Portugueses s/n - 65085-580 - Bacanga - São Luis - MA - Brasil - Phone: +55 9833018575 - e-mail: sosocarvalho@usp.br - emaildasoso@gmail.com

Received: September 18, 2010 - Modification: August 14, 2011 - Accepted: September 15, 2011

\section{ABSTRACT}

$\mathrm{O}$ bjective: The aim of this study was to compare the correspondence between gap formation and apical microleakage in root canals filled with epoxy resin-based (AH Plus) combined or not with resinous primer or with a dimethacrylate-based root canal sealer (Epiphany). Material and Methods: Thirty-nine lower single-rooted human premolars were filled by the lateral condensation technique (LC) and immersed in a $50-w t \%$ aqueous silver nitrate solution at $37^{\circ} \mathrm{C}(24 \mathrm{~h})$. After longitudinal sectioning, epoxy resin replicas were made from the tooth specimens. Both the replicas and the specimens were prepared for scanning electron microscopy (SEM). The gaps were observed in the replicas. Apical microleakage was detected in the specimens by SEM/energy dispersive spectroscopy (SEM/EDS). The data were analyzed statistically using an Ordinal Logistic Regression model and Analysis of Correspondence $(\alpha=0.05)$. Results: Epiphany presented more regions containing gaps between dentin and sealer $(p<0.05)$. There was correspondence between the presence of gaps and microleakage $(p<0.05)$. Microleakage was similar among the root-filling materials $(p>0.05)$. Conclusions: The resinous primer did not improve the sealing ability of AH Plus sealer and the presence of gaps had an effect on apical microleakage for all materials.

Key words: Electron microscopy. Leakage. Resin cements. Root canal obturation. Silver nitrate.

\section{INTRODUCTION}

It is generally accepted that microleakage between the filling materials and root canal walls might adversely affect the outcome of root canal treatment ${ }^{13}$. Therefore, it is critical the complete sealing of the root canal system after cleaning and shaping in order to avoid the bacterial penetration and re-infection of the root and periapical tissues ${ }^{3}$. The association of gutta-percha cones and root canal sealer has been traditionally used for this purpose. However, in the last decade, the dentin adhesive technology has been incorporated into the root canal filling techniques to reduce apical and coronal leakage by bonding to root canal walls ${ }^{28}$. Etch-and-rinse adhesives have been tested with resin cements ${ }^{10}$ and the combination of a dentinbonding agent and an epoxy resin-based root canal sealer significantly reduced apical leakage ${ }^{12}$.

In Restorative Dentistry, the self-etch adhesive systems have shown less technique sensitivity, with reliable long-term performance of a two-step mild self-etch adhesive ${ }^{5,30}$. Following this trend, Pentron Clinical Technologies (Wallingford, CT, USA) has developed the Epiphany system, which contains a self-etch primer, a dual-cured composite resin 
sealer and a polyester-based thermoplastic rootfilling material (Resilon ${ }^{\mathrm{TM}}$; Resilon Research LLC, Madison, CT, USA). According to Shipper, et al.23 (2004) this material has been shown to be more resistant to bacterial leakage than epoxy resinbased sealers for filling root canals.

In Endodontics, the controversy about the performance of adhesive systems inside the root canal remains ${ }^{1,21,26}$. Despite that, other possibility is combining Epiphany primer with $\mathrm{AH}$ Plus in an attempt to add the hybridization capacity to the gold standard endodontic sealer. The reason for this is that the removal of the smear layer with ethylenediamine tetraacetic acid (EDTA) does not provide the same etching pattern usually associated with the hybrid layer, which is considered an important factor for dentin bonding ${ }^{15,19}$.

The majority of studies have evaluated apical or coronal microleakage, and few have focused gap formation at the dentin/sealer interface ${ }^{1,26-28}$. So far, no correlation between microleakage and gap formation has been established in the literature. Thus, it is reasonable to believe that the association of both methods would provide a more precise evaluation of the adhesive interface.

The aim of this study was to compare the apical sealing and gap formation of $\mathrm{AH}$ Plus/gutta-percha with Epiphany system. In addition, the opportunity was taken to assess the effect of the association of Epiphany primer and AH Plus/gutta-percha on apical sealing and gap formation. The null hypotheses tested were as follows: (1) there is no difference in apical microleakage or (2) apical gap formation among the experimental groups and (3) there is no correspondence between apical microleakage and the presence of gaps.

\section{MATERIAL AND METHODS}

\section{Specimen preparation}

Thirty-nine lower single-rooted human premolars with straight root canals and fully developed apices (Local Ethics Committee approval 177/05) were cleaned and submitted to $18.5 \mathrm{KGy}$ gamacell radiation (Nuclear Energy Research Institute, São Paulo, SP, Brazil), and stored in saline solution at $4^{\circ} \mathrm{C}$. After endodontic access, the real working length (RWL) was established $1 \mathrm{~mm}$ short of the apical foramen. A crown-down technique was used (up to K-file \#50) under constant irrigation with $0.5 \% \mathrm{NaOCl}$. The smear layer was removed with $17 \%$ EDTA $(5 \mathrm{~mL})$ and $0.5 \% \mathrm{NaOCl}(5 \mathrm{~mL})^{31}$ followed by saline solution $(15 \mathrm{~mL})$. Root canals were dried with paper points. Afterwards, foramen diameter was standardized (\#30 K-file). Three coats of nail polish were applied to external root surfaces except for the apical $2 \mathrm{~mm}$.

The teeth were randomly (http://www.random. org) divided into 3 experimental groups $(n=11)$. This web-site allowed generating randomized sequences of integers. Six additional teeth were used for control. The endodontic sealers were prepared according to the manufacturer's instructions and the cold lateral condensation filling technique (LC) was used according with the following description:

\section{Group AH Plus}

An ISO \#50 master gutta-percha cone was lightly coated with $\mathrm{AH}$ Plus sealer ( $\mathrm{AH}$ Plus ${ }^{\circledR}$; Dentsply DeTrey, Konstanz, Germany) and placed into the canal to RWL. A size B finger spreader (Dentsply Maillefer, Ballaigues, Switzerland) was then inserted into the canal to a level approximately $1 \mathrm{~mm}$ short of RWL. LC with accessory gutta-percha cones was performed until the entirely filled root canal. The excess gutta-percha was removed with a heated plugger and then compacted vertically.

\section{Group AH Primer}

Adhesive-modified technique was used for bonding $\mathrm{AH}$ Plus to intraradicular dentin. A paper point soaked with Epiphany primer was used to etch dentin (30 s) and the excess was removed with paper points. The filling technique was the same of the group $\mathrm{AH}$ Plus.

\section{Group epiphany}

Dentin was etched as described for the $\mathrm{AH}$ Primer group. The LC was performed with Resilon cones and Epiphany sealer. The coronal surface of the root filling was light-cured for $40 \mathrm{~s}(600 \mathrm{~mW} /$ $\mathrm{cm}^{2}$ ).

\section{Positive and negative controls}

The positive controls $(n=3)$ were left unfilled and coated as described earlier. The negative controls $(n=3)$ were filled and totally coated, including the apical foramina.

The openings were sealed (Cavit ${ }^{\mathrm{TM}} \mathrm{W}, 3 \mathrm{M}$ ESPE, St Paul, MN, USA), and stored in a chamber held at $100 \%$ humidity and $37^{\circ} \mathrm{C}$ for 7 days. Next, all teeth were immersed in a 50-wt\% aqueous silver nitrate solution $\left(\mathrm{AgNO}_{3}, \mathrm{pH} \approx 7.0\right)$ in the darkness that was buffered using $\mathrm{NaOH} 0.1 \mathrm{~N}^{35}$ for $24 \mathrm{~h}$ at $37^{\circ} \mathrm{C}$. The silver-impregnated teeth were rinsed and placed in photodeveloper $(8 \mathrm{~h})$ in fluorescence light to reduce the silver ions into metallic silver ${ }^{4}$. They were embedded in epoxy resin (Epon-Thin ${ }^{\mathrm{TM}}$, Buhler Ltd., Lake Bluff, IL, USA), longitudinally sectioned in an Isomet 1000 Precision Saw (Buehler) at low speed (200 rpm) with a water-cooled diamond blade. The interfaces were etched with a $35 \%$ phosphoric acid solution (5 s), rinsed with distilled water (30 s) and gently air-dried. Then, specimen preparation followed the protocol 1 for apical microleakage analysis using scanning electron microscopy/energy 
dispersive spectroscopy (SEM/EDS); or the protocol 2 for gaps analysis using SEM according to the following description:

\section{Protocol 1}

Specimens were fixed, dehydrated in ascending grades of ethanol and final chemical drying in HMDS (Hexamethyldisilazane, Sigma-Aldrich Inc., St. Louis, MO, USA) for $10 \mathrm{~min}^{20}$, and covered with carbon (Sputter Coater SCD 050, BAL-TEC AG, Balzers, Liechtenstein). The apical $5 \mathrm{~mm}$ of the root canal filling were divided into 5 regions of $1 \mathrm{~mm}$ to evaluate microleakage by SEM LEO Stereoscan 440 (LEO Electron Microscopy Ltd., Cambridge, England) using back scattered electrons (BSE) mode (Figure 1a). The EDS (Inca software, Oxford, UK, England) was performed in lower magnification within a predetermined area $\left(300 \mu \mathrm{m}^{2}\right)$ (Figure $\left.1 \mathrm{~b}\right)$, and in a higher magnification, the identification of silver was made punctually to determine its exact location (Figure 1c). Each $1 \mathrm{~mm}$ region was classified according to the following scores: 0 (absence of leakage in both interfaces) and 1 (presence of leakage in at least one of the interfaces). In Figures $1 \mathrm{~d}$ and 1e typical spectrum showed higher or less $\mathrm{Ag}$ inside the interface.

\section{Protocol 2}

Impressions of polyvinyl siloxane Aquasil $^{\mathrm{TM}}$,
ULV, Dentsply DeTrey) were made of the interfaces and the surfaces replicated with epoxy resin (Epon-Thin $^{\mathrm{TM}}$, Buhler). The replicas were covered with carbon to investigate the presence of gaps at the dentin/sealer and sealer/cone interfaces, as described previously, using secondary electrons (SE) mode. As the gaps were not continuous, for each $1 \mathrm{~mm}$-region, two interfaces were analyzed (Figure 2a) and classified as: type 0: both interfaces were gap-free, type 1: gap at dentin/ sealer interface (Figure 2b), type 2: gap at sealer/ cone interface (Figure 2c), and type 3: both types of gaps present. Therefore, for each experimental group, 11 replicas were prepared; 55 regions were evaluated and accordingly classified.

The data obtained for apical microleakage and types of gaps were statistically analyzed ( $\alpha=0.05$ ) using the Ordinal Logistic Regression model ${ }^{9}$ and Correspondence Analysis ${ }^{7}$ in the MINITAB Statistical software program (Minitab Inc. Release 14 for Windows 2003, State College, PA, USA).

The counting of regions analyzed for gaps was also computed and adjusted in a Generalized Linear Model with Poisson distribution and logarithmic link function. The sealers groups (AH Plus, $\mathrm{AH}$ Primer and Epiphany) and the type of gap were considered as explanatory variables and $\mathrm{AH}$ Plus and the type 0 as references.

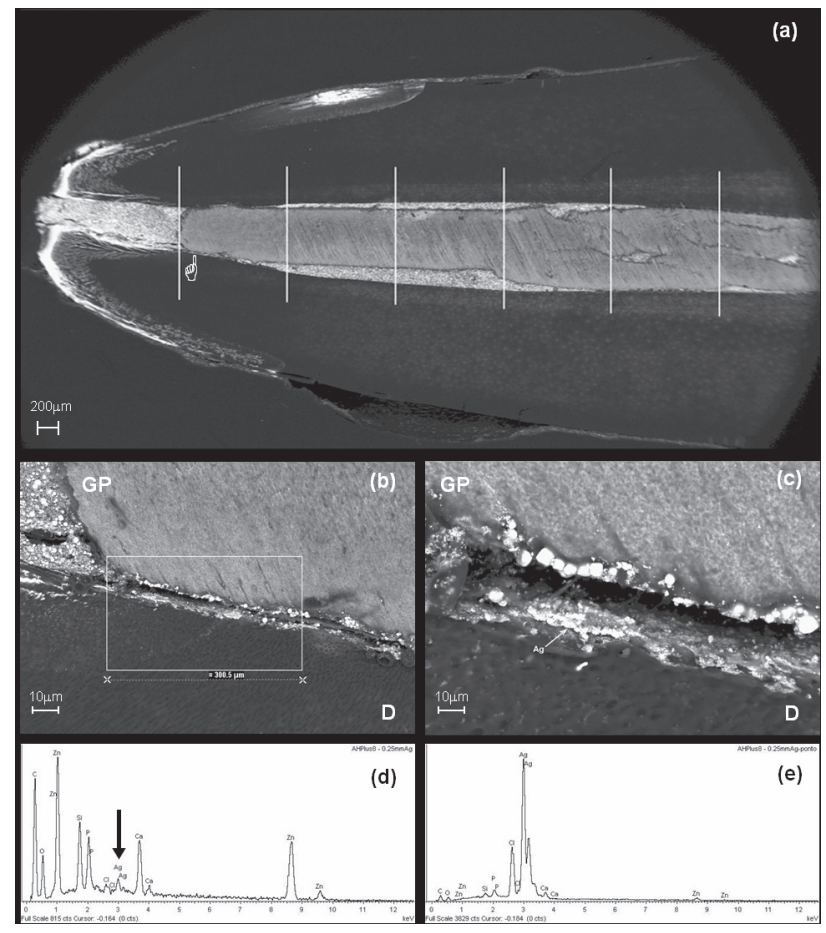

Figure 1-Scanning electron microscopy (SEM) micrographs using back scattered electrons (BSE) mode and corresponding energy dispersive spectroscopy (EDS) spectrum of $\mathrm{AgNO}_{3}$ leakage: (a) - The apical $5 \mathrm{~mm}$ of the root canal filling divided into $1 \mathrm{~mm}$-regions. Pointer at the detected metallic silver; (b) - area $\left(300 \mu \mathrm{m}^{2}\right)$ scanned for the existence of silver and respective EDS spectrum (arrow) and (c) - in detail, punctual EDS confirmation of its exact location. GP=Gutta-percha; $\mathrm{D}=$ Dentin 


\section{RESULTS}

The Ordinal Logistic Regression Analysis demonstrated that there was no statistically significant difference ( $p>0.05$ ) among the groups tested and types of gaps over the logit of microleakage. The model was adjusted to identify the effect of the type of gap on microleakage. The type 3 data were not considered isolated in the analysis (very few regions) but joined with type 2 data (Figure 2c; Table 1). The adjustment tests of the model presented high p-values for Pearson's test

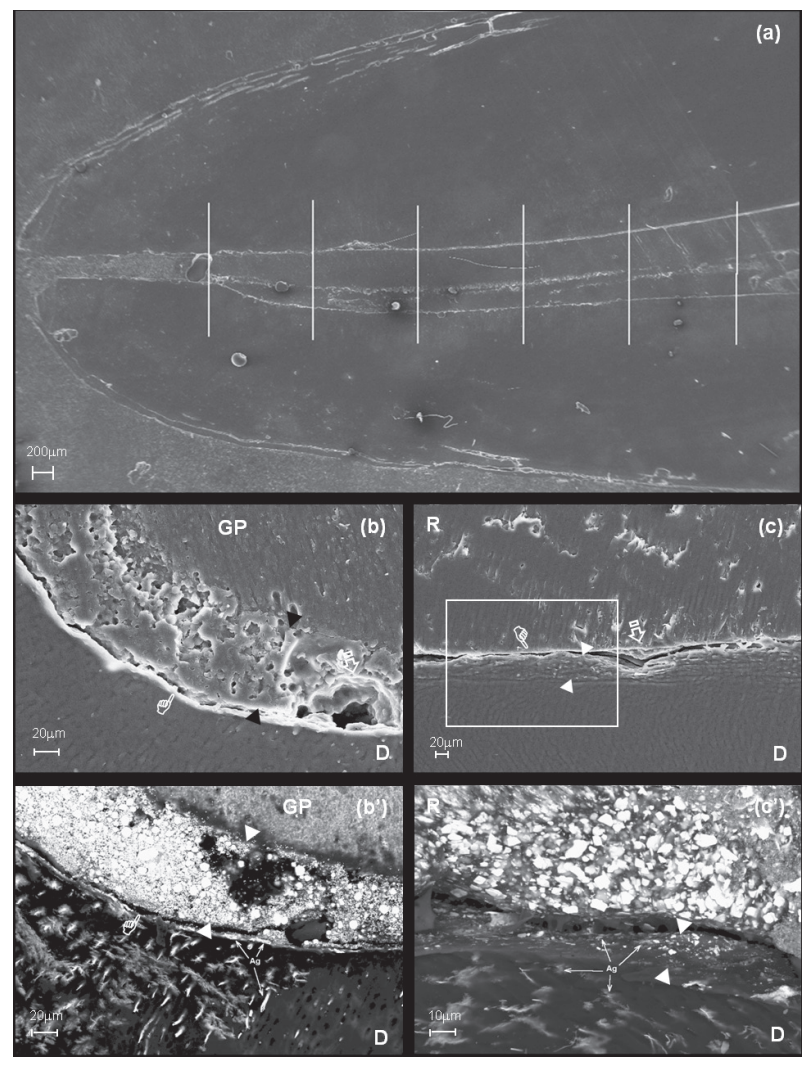

Figure 2- Scanning electron microscopy (SEM) micrographs using secondary electrons (SE) and back scattered electrons (BSE) mode of the replica and the section of the same specimen, respectively. (a) - The apical $5 \mathrm{~mm}$ of the root canal filling divided into $1 \mathrm{~mm}$ regions. Classification of the types of gaps: (b) - Type 1: gap between dentin/sealer (pointer); Air voids were present within the sealer (open arrow); (b') - Silver penetration was evident along the dentin/sealer interface, into dentinal tubules in a reticular form and granular aspect on the dentin surface (arrowhead); (c) - Type 2: gap between sealer/cone (pointer) - Cohesive fracture of the sealer (open arrow); (c') - the area marked in figure $C$ at higher magnification: Silver deposition into the dentinal tubules in a reticular form and granular aspect within the sealer layer (arrowhead) could be seen; (The sealer thickness was indicated between black/white arrowheads. GP=Gutta-percha; D=Dentin; R=Resilon) $(p=0.900)$ and Deviance $(p=0.852)$. The adjusted model demonstrated that the effect of the type of gap on the logit of microleakage is significant when compared to the presence of types 1 and 2 (Figure $2 \mathrm{~b}$ and $2 \mathrm{c}$, respectively) of gap with the absence of gap ( $p=0.047)$. The Correspondence Analysis also showed the association between microleakage and both types of apical gaps (Figure 3).

The Generalized Linear Model with Poisson distribution (Table 1) found no difference between $\mathrm{AH}$ Plus and $\mathrm{AH}$ Primer $(\mathrm{p}=0.497)$ in distribution of each type of gap, but they presented more type 0 regions $(p<0.001)$. There was a significant interaction between Epiphany and the type of gap $(p<0.003)$ and for this group, there were more type 1 regions.

Table 1- Frequency and type of gaps in the apical $5 \mathrm{~mm}$ of root canal fillings

\begin{tabular}{|c|c|c|c|c|}
\hline \multirow[t]{2}{*}{ Groups } & \multirow[t]{2}{*}{$\mathbf{n}$} & \multicolumn{3}{|c|}{ Frequency of gaps (\%)* } \\
\hline & & Type 0 & Type 1 & Type 2 \\
\hline $\mathrm{AH}$ Plus & 55 & $42(76)$ & $11(20)$ & $2(4)$ \\
\hline AH Primer & 55 & $36(65)$ & $14(26)$ & $5(9)$ \\
\hline Epiphany & 55 & $14(25)$ & $32(58)$ & $9(17)$ \\
\hline
\end{tabular}

*Percentage of regions with gaps. Type 0: absence of gaps; Type 1: gaps between dentin and sealer; Type 2: gaps between sealer and cone

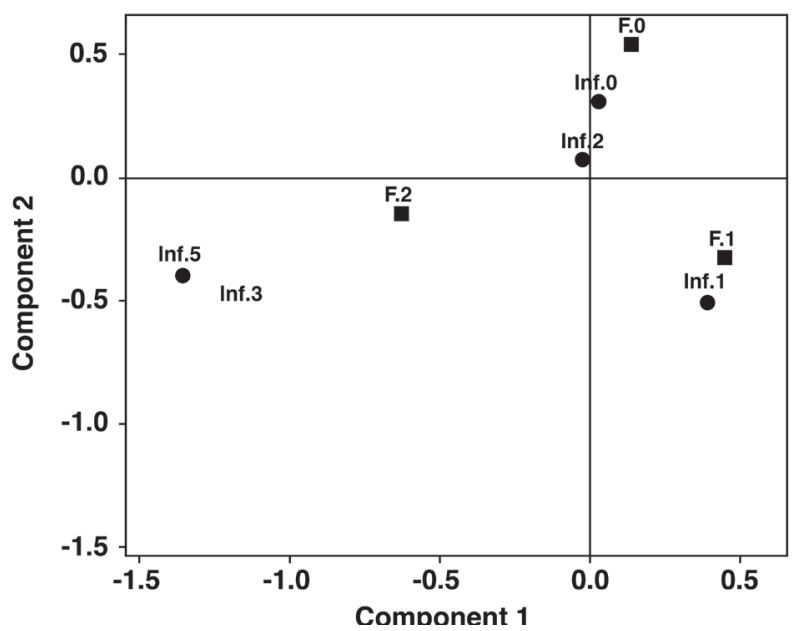

Figure 3-Correspondence analysis of microleakage vs. type of gap: (Inf.0) - absence of leakage; (Inf.1) - leakage up to the $1^{\text {st }}$ millimeter; (Inf.2) - leakage up to the $2^{\text {nd }} \mathrm{mm}$; (Inf.3) - leakage up to the $3^{\text {rd }}$ millimeter; (Inf.5) - leakage up to the $5^{\text {th }}$ millimeter; (F.0) - absence of gaps; (F.1) gaps type 1; (F.2) - gaps types 1 and 2. The absence of leakage is associated with the absence of gap; leakage up to the $1^{\text {st }}$ millimeter is associated with type 1 ; and more extensive leakage is associated with types 1 and 2 


\section{DISCUSSION}

Based on the findings of this study, the first null hypothesis could not be rejected. Recently some studies have shown similar results between AH Plus and Epiphany on apical sealing ability using the fluid filtration method ${ }^{18,22}$. Consistent with these studies, our results indicate that the Epiphany system is as effective as AH Plus/gutta-percha in preventing microleakage based on the chemical tracer penetration analysis by SEM and the use of Epiphany primer does not reduce the microleakage of $\mathrm{AH}$ Plus.

Nevertheless, other researches pointed out that the Epiphany system provided the greatest resistance to the movement of fluids ${ }^{25,29}$ or dye leakage test ${ }^{16}$, when compared to epoxy resin-based root canal sealers, but others have just indicated the opposite ${ }^{8,17}$. These apparent discrepancies can perhaps be explained by the methodology used and their variables ${ }^{6,16}$.

These results agree with those of previous studies in which, microleakage markers were used to evaluate apical sealing of the same endodontic sealers ${ }^{28,32}$. The tracer selected was $\mathrm{AgNO}_{3}$, which may penetrate into dentinal tubules due to their physical and chemical characteristics including: concentration, smaller molecular size, its neutral $\mathrm{pH}$, diffusion coefficient ${ }^{34}$ and service life up to 168 h post-preparation time of solution ${ }^{4}$. Another reason for this choice is that metallic silver deposits may be observed by SEM using back scattered electrons (BSE) mode 35 .

On the other hand, the results of the current study disagree with the findings of Shipper, et al. ${ }^{23}$ (2004) and Leonardo, et al. ${ }^{11}$ (2007). An explanation for this would be that their studies have evaluated coronal and not apical bacterial leakage. Indeed, coronal seal might be favorably influenced by photoactivation of the material which is unlikely to occur in the apical third ${ }^{14}$. Furthermore, it is speculated that in in vivo studies (dogs), the high release of calcium hydroxide ( $41.46 \mathrm{mg} / \mathrm{L}$ ) that would occur during the process of Epiphany sealer solubilization, would make the medium alkaline, resulting in acceleration of the periapical tissue repair process ${ }^{33}$.

This study has shown that the presence of apical gaps at the sealer/dentin or sealer/cone interfaces had an effect on apical microleakage. The Epiphany group presented more type 1 gaps than the other groups (Table 1), rejecting the second null hypothesis. These results corroborate with previous observation of gaps in the apical $4 \mathrm{~mm}$ of Epiphany or $\mathrm{AH}$ Plus-filled root canals ${ }^{28}$. Stress generated during the polymerization shrinkage of Epiphany sealer has probably influenced the integrity loss at the sealer/dentin interface ${ }^{24}$. In addition, the cavity configuration factor (C-factor) is highly unfavorable for adhesion inside root canals ${ }^{26}$. Moreover, it is known that analysis of gap formation of vertically sectioned root filled teeth hides the risk of artifacts during sectioning. Therefore, in this study, the sections were made at low speed under water cooling. The resin-epoxy replicas at the dentin/sealer and sealer/ cone interfaces were made before the specimens had been prepared for SEM examination in order to differentiate genuine gaps from artifactual gaps created after vacuum desiccation in conventional scanning electron microscopes. Besides, the replica analysis has to be regarded with caution ${ }^{20}$.

Few studies have focused on apical sealing from two separate perspectives, such as microleakage and apical gap formation. This inter-relationship has not been fully demonstrated in the literature. SEM was used to evaluate these perspectives ${ }^{1,26-28}$, but it was restricted to a descriptive approach.

A systematization of the observations, complemented by a statistical analysis, such as the one performed in this study, could provide greater methodological accuracy and impartiality for comparing the experimental groups. The Correspondence of Analysis between the types of gaps and linear extent of $\mathrm{AgNO}_{3}$ leakage (Fig. 3) confirms the effect of gaps on apical microleakage, expressed by the silver deposition into gaps that extended deeply inside dentinal tubules (Fig. 2b' and $\left.c^{\prime}\right)$, rejecting the third null hypothesis.

Regarding to statistical analysis, the Ordinal Logistic Regression Analysis Model was used due to microleakage was considered categorized ordinal response variable (ranging from 0 - no leakage to 5 - leakage up to the fifth millimeter). The Correspondence Analysis is a method that leads to visualize the association between two categorical variables, in this case microleakage and the type of gap. The Generalized Linear Model with Poisson which is an extension of usual regression model was performed to quantify the distribution of types of gaps. This result could be explained by two hypotheses: (1) the low degree of conversion of the Epiphany sealer ${ }^{2}$ and (2) the formation of hydrogel at the bond interface resulting from the incomplete evaporation of the Epiphany primer solvent ${ }^{3}$. The second hypothesis could also explain the inefficacy of Epiphany primer in improving the sealing capacity of AH Plus. Moreover, there is a chemical incompatibility between these two materials, since the epoxy resin sealers do not copolymerize with methacrylate resinbased adhesives ${ }^{28}$. Other studies should be carried out to clarify the sealing ability of the root-filled materials studied.

\section{CONCLUSIONS}

It may be concluded that none of the tested materials completely sealed the apical $5 \mathrm{~mm}$. The 
Epiphany primer did not improve the sealing capacity of AH Plus sealer. The presence of gaps had an effect on apical microleakage for all materials. Comparing the materials, Epiphany system presented more regions containing gaps between the dentin and the sealer (type 1). In view of these findings, clinically, it can be suggested that $\mathrm{AH}$ Plus would provide a better apical seal.

\section{ACKNOWLEDGEMENTS}

This study was partially supported by CAPES (Coordenação de Aperfeiçoamento de Pessoal de Nível Superior)/Institutional Qualification Program (PQI no: 0090/03-4).

\section{REFERENCES}

1- Bergmans L, Moisiadis P, De Munck J, Van Meerbeek B, Lambrechts P. Effect of polymerization shrinkage on the sealing capacity of resin fillers for endodontic use. J Adhes Dent. 2005;7:321-9.

2- Beriat NC, Ertan A, Cehreli ZC, Gulsahi K. Time-dependent conversion of a methacrylate-based sealer polymerized with different light-curing units. J Endod. 2009;35:110-2.

3- Bouillaguet S, Shaw L, Barthelemy J, Krejci I, Wataha JC. Longterm sealing ability of Pulp Canal Sealer, AH-Plus, GuttaFlow and Epiphany. Int Endod J. 2008;41:219-26.

4- Costa JF, Siqueira WL, Loguércio $A D$, Reis A, Oliveira E, Alves $C M$, et al. Characterization of aqueous silver nitrate solutions for leakage tests. J Appl Oral Sci. 2011;19:254-9.

5- De Munck J, Van Landuyt K, Peumans M, Poitevin A, Lambrechts $\mathrm{P}$, Braem M, et al. A critical review of the durability of adhesion to tooth tissue: methods and results. J Dent Res. 2005;84:118-32. 6- Dultra F, Barroso JM, Carrasco LD, Capelli A, Guerisoli DM, Pécora JD. Evaluation of apical microleakage of teeth sealed with four different root canal sealers. J Appl Oral Sci. 2006;14:341-5. 7- Greenacre M. Correspondence analysis in pratice. London: Chapman \& Hall; 2007.

8- Hirai VH, Silva Neto UX, Westphalen VP, Perin CP, Carneiro E, Fariniuk LF. Comparative analysis of leakage in root canal fillings performed with gutta-percha and Resilon cones with AH Plus and Epiphany sealers. Oral Surg Oral Med Oral Pathol Oral Radiol Endod. 2010;109:e131-5.

9- Hosmer DW, Lemeshow S. Applied logistic regression. New York: John Wiley \& Sons; 1989.

10- Leonard JE, Gutmann JL, Guo IY. Apical and coronal seal of roots obturated with a dentine bonding agent and resin. Int Endod J. $1996 ; 29: 76-83$.

11- Leonardo MR, Barnett F, Debelian GJ, Pontes Lima RK, Bezerra da Silva LA. Root canal adhesive filling in dogs' teeth with or without coronal restoration: a histopathological evaluation. J Endod. 2007;33:1299-303.

12- Mannocci F, Ferrari M. Apical seal of roots obturated with laterally condensed gutta-percha, epoxy resin cement, and dentin bonding agent. J Endod. 1998;24:41-4.

13- Mannocci F, Innocenti M, Bertelli E, Ferrari M. Dye leakage and SEM study of roots obturated with Thermafill and dentin bonding agent. Endod Dent Traumatol. 1999;15:60-4.

14- Nagas E, Cehreli ZC, Durmaz V, Vallittu PK, Lassila LV. Regional push-out bond strength and coronal microleakage of Resilon after different light-curing methods. J Endod. 2007;33:1464-8.

15- Nunes VH, Silva RG, Alfredo E, Sousa-Neto MD, Silva-Sousa YT. Adhesion of Epiphany and AH Plus sealers to human root dentin treated with different solutions. Braz Dent J. 2008;19:46-50.

16- Oddoni PG, Mello I, Coil JM, Antoniazzi JH. Coronal and apical leakage analysis of two different root canal obturation systems. Braz Oral Res. 2008;22:211-5.
17- Onay EO, Ungor M, Unver S, Ari H, Belli S. An in vitro evaluation of the apical sealing ability of new polymeric endodontic filling systems. Oral Surg Oral Med Oral Pathol Oral Radiol Endod. 2009; 108:e49-54.

18- Paqué F, Sirtes G. Apical sealing ability of Resilon/Epiphany versus gutta-percha/AH Plus: immediate and 16 -months leakage. Int Endod J. 2007;40:722-9.

19- Pashley DH, Ciucchi B, Sano H, Carvalho RM, Russell CM. Bond strength versus dentine structure: a modelling approach. Arch Oral Biol. 1995;40:1109-18.

20- Perdigão J, Lambrechts P, Van Meerbeek B, Vanherle G, Lopes AL. Field emission SEM comparison of four postfixation drying techniques for human dentin. J Biomed Mater Res. 1995;29:111120.

21- Perdigão J, Lopes MM, Gomes G. Interfacial adaptation of adhesive materials to root canal dentin. J Endod. 2007;33:259-63. 22- Raina R, Loushine RJ, Weller RN, Tay FR, Pashley DH. Evaluation of the quality of the apical seal in Resilon/Epiphany and GuttaPercha/AH Plus-filled root canals by using a fluid filtration approach. J Endod. 2007;33:944-7.

23- Shipper G, Ørstavik D, Teixeira FB, Trope M. An evaluation of microbial leakage in roots filled with a thermoplastic synthetic polymer-based root canal filling material (Resilon). J Endod. 2004;30:342-7.

24- Souza SFC, Bombana AC, Francci C, Goncalves F, Castellan C, Braga RR. Polymerization stress, flow and dentine bond strength of two resin-based root canal sealers. Int Endod J. 2009;42:867-73. 25- Stratton RK, Apicella MJ, Mines P. A fluid filtration comparison of gutta-percha versus Resilon, a new soft resin endodontic obturation system. J Endod. 2006;32:642-5.

26- Tay FR, Loushine RJ, Lambrechts P, Weller RN, Pashley DH. Geometric factors affecting dentin bonding in root canals: a theoretical modeling approach. J Endod. 2005;31:584-9.

27- Tay FR, Loushine RJ, Monticelli F, Weller RN, Breschi L, Ferrari M, et al. Effectiveness of resin-coated gutta-percha cones and a dualcured, hydrophilic methacrylate resin-based sealer in obturating root canals. J Endod. 2005;31:659-64.

28- Tay FR, Loushine RJ, Weller RN, Kimbrough WF, Pashley DH, Mak $Y F$, et al. Ultrastructural evaluation of the apical seal in roots filled with a polycaprolactone-based root canal filling material. J Endod. 2005;31:514-9.

29- Tunga $U$, Bodrumlu E. Assessment of the sealing ability of a new root canal obturation material. J Endod. 2006;32:876-8.

30- Van Meerbeek B, De Munck J, Yoshida Y, Inoue S, Vargas M, Vijay $P$, et al. Buonocore memorial lecture. Adhesion to enamel and dentin: current status and future challenges. Oper Dent. 2003;28:215-35.

31- Vasconcelos BC, Luna-Cruz SM, De-Deus G, Moraes IG, ManigliaFerreira C, Gurgel-Filho ED. Cleaning ability of chlorhexidine gel and sodium hypochlorite associated or not with EDTA as root canal irrigants: a scanning electron microscopy study. J Appl Oral Sci. 2007; 15:387-91.

32- Verissimo DM, Vale MS, Monteiro AJ. Comparison of apical leakage between canals filled with gutta-percha/AH-Plus and the Resilon/Epiphany System, when submitted to two filling techniques. J Endod. 2007;33:291-4.

33- Versiani MA, Carvalho-Junior JR, Padilha MI, Lacey S, Pascon EA, Sousa-Neto MD. A comparative study of physicochemical properties of AH Plus and Epiphany root canal sealants. Int Endod J. 2006;39:464-71.

34- Wu MK, Wesselink PR. Endodontic leakage studies reconsidered. Part I. Methodology, application and relevance. Int Endod J. 1993;26:37-43.

35- Youngson CC, Jones JC, Manogue M, Smith IS. In vitro dentinal penetration by tracers used in microleakage studies. Int Endod J. 1998;31:90-9. 